\title{
Avaliação da qualidade das áreas verdes urbanas de Ponta Grossa, PR, Brasil
}

\author{
Evaluación de la calidad de las areas verdes urbanas de Ponta \\ Grossa, PR, Brasil
}

\section{Evaluation of the quality of urban green areas in Ponta Grossa, PR, Brazil}

\author{
Dulcina de Aquino Hernandez de Oliveira Queiroz \\ dulcinah@gmail.com \\ Universidade Estadual de Ponta Grossa, UEPG, Ponta Grossa, PR \\ Silvia Méri Carvalho \\ silviameri@brturbo.com.br \\ Universidade Estadual de Ponta Grossa, UEPG, Ponta Grossa, PR
}

Resumo: As áreas verdes têm sido apontadas como elementos fundamentais para sustentabilidade na área urbana, funcionando não somente como amenidades físicas, mas também como elementos de valorização espacial. No entanto, considera-se que sua simples presença não é suficiente para atender as necessidades dos habitantes. Este artigo apresenta uma metodologia para avaliar de forma qualitativa as áreas verdes em área urbana, por meio de um índice composto - IQAVU, que considera três sub índices: Função Ambiental, Função Social e Função Estética. Cada sub índice congrega três indicadores que permitem traçar o perfil das áreas verdes, apontando as suas fragilidades e possíveis áreas intervenção. O resultado de 0.38 para o IQAVU da cidade de Ponta Grossa apontou para a baixa qualidade destes espaços (ambiental $=0.21$; social=0.57; estética $=0.45$ ). Porém, mais que o significado de um valor numérico, a potencialidade deste índice para o planejamento urbano reside na identificação da função que está mais debilitada, neste caso, a função ambiental.

Palavras-chave: Planejamento urbano; Função Ambiental; Função Social; Funçao Estética.

Resumen: Las áreas verdes se han apuntado como elementos fundamentales para la sostenibilidad en el área urbana, funcionando no sólo como amenidades físicas, sino también como elementos de valorización espacial. Sin embargo, se considera que la simple presencia no es suficiente para atender las necesidades de los habitantes. En este contexto, el presente artículo presenta una metodología para evaluar de forma cualitativa las áreas verdes urbanas a través de un índice compuesto - IQAVU, que considera tres sub índices: Función Ambiental, Función Social y Función Estética. Cada sub índice congrega tres indicadores que permiten trazar el perfil de las áreas verdes, apuntando a sus fragilidades y posibles áreas intervención. Ponta Grossa presentó um bajo índice de 0.38 (ambiental $=0.21$; social $=0.57$; estética $=0.45$ ). Sin embargo, más que el significado de un valor numérico, la potencialidad de este índice reside en la identificación de la función más debilitada, en este caso, la función ambiental.

Palabras clave: Planificación urbana; función ambiental, función social, función estética. 


\begin{abstract}
The green areas have been identified as fundamental elements for sustainability in the urban area, functioning not only as physical amenities but also as elements of spatial appreciation. However, it is considered that its mere presence is not enough to achieve the needs of the inhabitants. In this paper, we present a methodology for qualitatively evaluating green urban areas by means of a composite index, which considers three sub-indexes: Environmental Function, Social Function, and Aesthetic Function. Each sub-index contains three indicators that allow tracing the profile of green areas, pointing out their frailties and possible intervention areas. Ponta Grossa has a low index of 0.38 (environmental $=0.21$; social $=0.57$; aesthetic $=0.45$, however, more than the meaning of a numerical value, the potentiality of this index resides in the identification of which function is unsuitable, in this case, the environmental one.
\end{abstract}

Keywords: Urban planning; Environmental Function; Social Function; Aesthetic Function.

\title{
INTRODUÇÃO
}

O ambiente urbano desenvolveu-se intensamente a partir da década de 1950 no Brasil, em grande parte, em função de fluxos migratórios direcionados às grandes cidades. Nesse contexto, o processo de urbanização, responsável pelo consumo de espaço e especulação imobiliária, passa a intensificar-se também e, consequentemente a dar visibilidade ao fenômeno, uma vez que a qualidade de vida dos seus habitantes é fortemente afetada. Por isso, planejamento e regulamentação urbanos tornam-se necessários (AMORIM FILHO; SERRA, 2001; NASCIMENTO; MATIAS, 2011) para oferecer melhores condições de vida aos seus habitantes, seja por oferecer boas condições viárias, serviços públicos ou boa infraestrutura e amenidades físicas, como é o caso de áreas verdes.

Particularmente, as cidades médias apresentaram maior crescimento dos índices econômicos e de taxas de urbanização, que associado a um planejamento inadequado, pode comprometer a qualidade de equipamentos e prestação de serviços públicos. $O$ planejamento quando eficaz, torna-se vital para oferecer melhores condições de vida aos seus habitantes, seja por oferecer boas condições viárias, serviços públicos ou boa infraestrutura e amenidades físicas, como é o caso de áreas verdes.

As amenidades físicas que valorizam o espaço, para Corrêa (1995), são especialmente sensíveis em um cenário de crescimento desordenado e especulativo, muito comum, onde a ocupação do solo acontece de forma muito rápida em razão da exigência e pressão por demanda de espaço urbanizado. Resultando em um planejamento deficitário, descomprometido social e espacialmente com a comunidade em geral (SILVA, 2014).

Simultaneamente são cada vez mais perceptíveis os benefícios das áreas verdes a toda a população, sobretudo em termos de microclima, drenagem e biodiversidade, além da recreação, lazer e convívio. Destaca-se ainda a importante atuação das áreas verdes na valorização visual e ornamental, devido contraposição que fazem ao ambiente construído, no suporte a atividades recreativas e na reconexão da população com a natureza (CAVALHEIRO; DEL PICCHIA, 1992; NUCCI, 2008; AZEVEDO; GONÇALVES, 2010; RUMBLE et al., 2019). Assim, o planejamento adequado é a melhor estratégia, sobretudo 
para as cidades médias, uma vez que, por meio do ordenamento territorial, poderá se evitar ou minimizar os já conhecidos problemas associados ao crescimento urbano das grandes metrópoles.

A cidade de Ponta Grossa, com cerca de 350.000 habitantes (IBGE, 2018) caracterizase como sendo de porte médio (SPOSITO, 2010; CONTE, 2013; SILVA, 2013). No entanto, como afirma Silva (2013), considerar apenas o número de habitantes na classificação de uma cidade intermediária é uma visão simplista e redutora, pois o "entendimento da cidade média perpassa pelas funções que ela desempenha na rede urbana na intermediação regional" (SILVA, 2013, p. 64). Mesmo nesta perspectiva é possível reconhecer a cidade de Ponta Grossa como sendo de porte médio, uma vez que sua economia se deve, em grande parte, pelas atividades industriais voltadas para os segmentos metalquímico, de químicos, plásticos e de alimentos, agregada a um diversificado setor de comércio e serviços, por constituir-se em um importante entroncamento rodoferroviário (SAHR, 2001).

O estudo de Queiroz (2014), que mapeaou as áreas verdes na área urbana de Ponta Grossa e o cálculo do índice de área verde por habitante, demonstrou, aparentemente, um cenário positivo. No entanto, considerou-se essa leitura numérica muito redutora, uma vez que a efetividade das funções das áreas verdes nos aspectos ambiental, social e estético não foi demonstrada. $\mathrm{O}$ aprofundamento dessa pesquisa não se fundamenta apenas em quantidade de área por habitante, mas considera a função ambiental, social e estética, fornecendo ao poder público um diagnóstico preciso.

Estudos que envolvem o conceito de área verde, um termo relativamente novo e conhecido globalmente, apontam para um problema comum que é a diversidade de significados. O maior consenso está no fato de se reconhecer que as áreas verdes constituem um tipo de espaço livre, enquadrado no "sistema de espaços livres de construção", onde predomina a presença de vegetação de porte arbóreo que potencialmente desempenharia as funções ambientais, sociais e estéticas. (NUCCI et al., 2003; NUCCI, 2008, BARGOS, 2012). Diante disto, o objetivo deste artigo é avaliar a qualidade das áreas verdes da cidade, por meio de um índice que considere o cumprimento das suas funções.

\section{PROPOSTA METODOLÓGICA DE ÍNDICE DE QUALIDADE DAS ÁREAS VERDES URBANAS (IQAVU)}

A aplicação de índices em trabalhos de pesquisa, sob a ótica de diversas ciências, é assumida como importante ferramenta de avaliação. Esses índices apresentam vantagens na simplificação, quantificação e expressão de forma resumida de fenômenos complexos e podem ser de natureza temática única ou variada, de agregação de dados simples ou compostos ou até mesmo agregado a outros índices (NAHAS, 2001; SANTOS, 2004).

Em particular, para a análise de áreas verdes urbanas, os índices mais encontrados na literatura privilegiam a relação $\mathrm{m}^{2}$ por habitante, sugeridos por Cavalheiro e Del Picchia (1992) e adotados por Guzzo (1999) e Harder, Roberval e Tavares (2006), como demonstrado no Quadro 1. 
Quadro 1: Diferentes índices utilizados na análise de áreas verdes urbanas

\begin{tabular}{|l|l|}
\hline \multicolumn{1}{|c|}{ ÍNDICE } & \multicolumn{1}{c|}{ DESCRIÇÃO } \\
\hline $\begin{array}{l}\text { O índice de Áreas Verdes para } \\
\text { Parque de Vizinhança (IAVPV) }\end{array}$ & $\begin{array}{l}\text { Somatório das áreas verdes de parque de vizinhança dividido pelo número } \\
\text { de habitantes da área urbana. }\end{array}$ \\
\hline $\begin{array}{l}\text { Índice de Áreas Verdes para Parque } \\
\text { de Bairro (IAVPB) }\end{array}$ & $\begin{array}{l}\text { Somatório das áreas verdes de parque de bairro dividido pelo número de } \\
\text { habitantes da área urbana. }\end{array}$ \\
\hline $\begin{array}{l}\text { Índice de Áreas Verdes Utilizáveis } \\
\text { (IAVU) }\end{array}$ & $\begin{array}{l}\text { Somatório das áreas de praças totalmente utilizáveis dividido pelo número de } \\
\text { habitantes da área urbana. }\end{array}$ \\
\hline Índice de Cobertura Vegetal (ICV). & $\begin{array}{l}\text { Somatório das áreas de copa dividido pelo número de habitantes da área } \\
\text { urbana. }\end{array}$ \\
\hline $\begin{array}{l}\text { Índice de Espaços Livres de Uso } \\
\text { Público (IELUP) }\end{array}$ & $\begin{array}{l}\text { Expresso em m²/hab), que é a quantidade de área de espaços livres urbanos } \\
\text { de uso público, ou seja, as áreas cujo acesso das pessoas é livre. São somadas } \\
\text { nesse cálculo as áreas de praças, parques, sistemas de lazer e cemitérios. }\end{array}$ \\
\hline $\begin{array}{l}\text { Índice de Cobertura Vegetal em } \\
\text { Área Urbana (ICVAU) }\end{array}$ & $\begin{array}{l}\text { Expresso em porcentagem, que representa a proporção de área coberta com } \\
\text { vegetação, em função da área total estudada. Ele abrange as áreas públicas e } \\
\text { particulares. }\end{array}$ \\
\hline $\begin{array}{l}\text { O Índice de Verde por Habitante } \\
\text { (IVH) }\end{array}$ & $\begin{array}{l}\text { Expressa a quantidade de cobertura vegetal dividida pelo número de } \\
\text { habitantes do local. }\end{array}$ \\
\hline
\end{tabular}

Org: as autoras.

Apesar de serem válidos estes índices, o seu uso poderá mascarar a realidade sobre as condições das áreas verdes, uma vez que retratam única e exclusivamente a relação espacial, desconsiderando outras variáveis imprescindíveis na caracterização de áreas verdes.

Acredita-se que, por meio de um conjunto de indicadores de base, seja possível fazer uma avaliação sobre os principais benefícios disponibilizados pelas áreas verdes urbanas, com o objetivo de contribuir para uma melhor compreensão sobre a qualidade de vida, de um modo eficaz e perceptível para tomadores de decisão.

O índice de qualidade das áreas verdes urbanas (IQAVU) é um índice composto por três sub-índices, que retratam as funções desempenhadas pelas áreas verdes: ambiental, social e estética. Estes sub-índices são compostos por um conjunto de indicadores (Quadro 2) que definem dados, informações e valores, que resultam ao final numa avaliaçãoo da situação das áreas verdes. 
Quadro 2: Esquema teóricos dos elementos que integram o IQAVU.

\begin{tabular}{|c|c|c|c|}
\hline ÍNDICE COMPOSTO & FUNÇÕES & INDICADORES & DADOS ANALISADOS \\
\hline \multirow{9}{*}{$\begin{array}{l}\text { ÍNDICE DE } \\
\text { QUALIDADE DAS } \\
\text { ÁREAS VERDES } \\
\text { URBANAS (IQAVU) }\end{array}$} & \multirow{3}{*}{ Função Ambiental (FA) } & $\begin{array}{l}\text { Índice de cobertura arbórea } \\
\text { (ICA) }\end{array}$ & Área de copa/área urbana total \\
\hline & & $\begin{array}{c}\text { Presença de espécies nativas } \\
(\text { EN) }\end{array}$ & $\%$ de espécies nativas \\
\hline & & Fragmentação (FRAG) & Isolado/ Linear / conectado \\
\hline & \multirow{3}{*}{ Função Social (FS) } & Justiça da distribuição (JD) & Índice de Jain \\
\hline & & Categorias das áreas verdes $(\mathrm{C})$ & $\begin{array}{l}\text { Público/ potencialmente } \\
\text { coletivos / privados }\end{array}$ \\
\hline & & $\begin{array}{c}\text { Presença de equipamentos de } \\
\text { lazer (EL) }\end{array}$ & Presença / Ausência \\
\hline & \multirow{3}{*}{ Função Estética (FE) } & Mobiliário urbano (MU) & Conservação, Conforto \\
\hline & & Pavimentos (PAV) & Conservação, Segurança \\
\hline & & Elemento água (EA) & Presença / Ausência \\
\hline
\end{tabular}

Org: as autoras.

A caracterização da Função Ambiental (FA) das áreas verdes no espaço considera que o cumprimento da função ambiental está diretamente relacionado e interligado à presença de vegetação nestes locais. (NUCCI, 2008). Corrabora-se Llandert (1982) ao afirmar que as funções ambientais, por ele denominadas como ecológicas, podem ser divididas em dois grandes grupos: relação clima-solo-vegetação e composição atmosférica e ruídos. Em cada um dos grupos, identificam-se várias funções da arborização que geram implicações ecológicas.

No âmbito clima-solo-vegetação, a atuação da cobertura de vegetação urbana, dependendo das suas características, se dá por meio da interceptação, reflexão, absorção e transmissão da radiação direta ou refletida e pela manutenção de elevadas taxas de absorção, pode levar à diminuição da temperatura e das amplitudes térmicas e/ouou manter a umidade do ar, o que proporciona maior conforto térmico e luminoso não somente às pessoas mas também às espécies animais e da flora, e manutenção do clima local. Relacionado ao porte da vegetação, uma média de 60 a 75\% da energia solar incidente é consumida pelos processos fisiológicos fornecendo um equilíbrio por meio de trocas pelo ar.

A vegetação, sobretudo arbórea, proporciona também proteção física e estabilizadora de raízes e intercepta, por meio da folhagem, as gotas da chuva que impedem a destruição do horizonte superficial dos solos. A presença de vegetação permite que 15 a $35 \%$ da energia recebida sejam absorvidas, o que favorece à conservação da umidade do solo e atenua o aquecimento (BERNATZKY,1992; LLANDERT, 1992, com implicações diretas na prevenção de deslizamentos e na redução dos custos no tratamento de águas para abastecimento, já que os solos têm ação filtrante das águas (OLIVEIRA, 1996; BOLUND; HUNHAMMAR, 1999). Quando a vegetação é constituida sobretudo por espécies de porte arbóreo, amplifica-se a gama de benefícios e funções ambientais, principalmente porque nas áreas urbanas são estes espaços que acomodam pequenos grupos de animais e plantas (LINDENMAIER, 2013). 
A vegetação pode ser vista de uma perspectiva tridimensional, como afirma Almeida (2015), pela possibilidade de ser analisada partindo do solo, mas também pelo volume de ar que ocupa. Particularmente esta última está intimamente ligada ao grau de sombreamento, no caso essa vegetação ser de porte arbóreo, já que o papel ambiental de um metro quadrado de árvore não é o mesmo que um metro quadrado de um estrato herbáceo ou arbustivo.

Outra variável que também é inevitavelmente afetada pela presença da vegetação, sobretudo de porte arbóreo, é a composição atmosférica das áreas urbanas, que é caracterizada pela presença de grande quantidade de gases e metais pesados, afetando, desse modo, a saúde dos que habitam nesse meio. Por meio do processo de fotossíntese, é realizada uma ação purificadora na produção do oxigênio que reduz significativamente os poluentes gasosos do ambiente atmosférico (BERNATZKY,1992; LLANDERT, 1992; DETZEL, 1992).

A ação mitigadora da vegetação está relacionada à diminuição do desconforto sonoro que se verifica nas cidades, devido à intensidade de tráfego e concentração de atividades industriais e comerciais. Por exemplo, espécies prenifólias apresentam maior eficácia na absorção das ondas sonoras do que espécies decíduas, já que estas refletem mais que as anteriores, pois as folhas funcionam como barreira das ondas alterando a sua energia e reconfigurando o som produzido (FORMAN; GODRON, 1986). Destaca-se também os benefícios da vegetação à fauna silvestre, cuja presença é fundamental para o estreitamento da relação do ser humano com a natureza; para o equilibrio das cadeias alimentares; para a conservação da fauna local, sobretudo se a vegetação for nativa, onde poderá haver uma considerável diminuição de pragas e agentes; em suma, para o equilibrio e harmonia do ecossistema urbano (BRUN et al., 2007; SPOSITO, 2010; ALMEIDA; ZEM; BIONDI, 2009; RUMBLE et al., 2019). Portanto, dada a importância do porte arbóreo, o IQAVU considera a porcentagem de cobertura arbórea das áreas verdes na área urbana.

Outra situação a destacar são os problemas ambientais ocasionados pela presença de espécies invasoras, sobretudo pelas consequências negativas que elas exercem nos ecossistemas hidrológicos, no ciclo de nutrientes ou erosão do solo, na produtividade vegetativa, nas cadeias tróficas e funções das espécies, na distribuição e acumulação da biomassa, entre outros, como também na saúde humana através da proliferação de alergias (MARCHANT; MARCHANT, 2007). Perante tal cenário, é relevante ao planejamento urbano considerar a presença de espécies nativas, em detrimento de invasoras, dado incorporado neste índice.

Para avaliar a contribuição ambiental de uma área verde em uma cidade, na opinião de Thompson (2002), deve-se observar o tamanho da mancha, a presença de rede de corredores e mosaicos das áreas verdes. É relevante reconhecer o valor ecológico dos espaços informais, ou seja, espaços aparentemente inúteis, os quais a autora denomina de "desarrumado", pois muitas vezes acabam sendo tão valiosos quanto o "arrumado" e o formal. Portanto a avaliação da função ambiental incide também sobre a atribuição de um valor na espacialização das manchas de cobertura arbórea no recorte urbano. Para isso utiliza-se a metodologia de classificação das diferentes formas geométricas da cobertura arbórea (JIM, 1989). 
No caso da Função Social (FS) a perspectiva utilizada para definir sua relação com as áreas verdes está na oferta de lazer e recreação, por meio da presença de infraestrutura adequada para tal, cuja eficiência depende de a distribuição oportunizar o acesso a espaços de lazer e valor natural a toda a população, sem levar em conta a classe social ou outras formas de diferenciação.

Para avaliar espacialmente a distribuiçao das áreas verdes destaca-se a pertinência do emprego do Índice de Jain, o qual traduz numericamente o grau de justiça da distribuição desse recurso em toda a área urbana.

O Índice de Jain ou Índice de Justiça (IJ) foi proposto por Jain, Chiu e Hawe (1984), com o objetivo de mensurar o nível de justiça na distribuição de uma determinada quantidade de recursos entre diferentes entidades de um grupo. Ele resulta em um número real no intervalo de 0 a 1 , onde valores mais próximos de 1 indicam uma distribuição "justa", ao passo que valores próximos de zero indicam uma distribuição "injusta" (JAIN; CHIU; HAWE,1984).

A função social considera que quando as áreas verdes são integradas ao meio urbano, como elementos de gestão pública, ou seja, que possam ser utilizados pela coletividade, tal condição potencializa os seus benefícios. Acredita-se que a categoria pública é uma das estratégias sociais mais importantes a ser levada em conta na hora de projetar uma cidade (DELGADO, 2011). Dentro desta concepção, o desempenho do componente social das áreas verdes, é reforçado quando está associado ao serviço de um espaço de categoria pública, por permitir uma melhor partilha e interação dos seus usuários, sem privilegiar os locais de moradores com poder aquisitivo maior, mas sim estender os benefícios para se atingir a uma equidade social.

A Função Estética (FE) das áreas verdes, de forma geral, deve estar relacionada com a capacidade destes elementos diversificarem a paisagem visando ao embelezamento das cidades. Para isso, pensar em critérios para avaliar essa função torna-se uma tarefa complexa já que se corre o risco de entrar no campo da percepção e do relativo. No entanto é indiscutível a importância desta funcionalidade, pois são espaços preferenciais para contemplação, entre outros.

$\mathrm{Na}$ tentativa de ultrapassar essa dificuldade, recorreu-se à perspectiva que a arquitetura detém, no seu domínio teórico, ao determinar que a total liberdade criativa do arquiteto influencia inevitavelmente os seus desenhos. No entanto, para Lamas (2004), o espaço assume o papel de protagonista por ser artificialmente modificado pelo homem que objetiva dar as condições apropriadas para realizar as suas atividades e criações. Assim, pensar e planejar áreas verdes esteticamente funcionais, apesar de subjetivo, deve considerar a existência de diretrizes pelas quais se podem guiar.

Concretamente, o princípio da contribuição estética das áreas verdes se assenta no embelezamento urbano, no rompimento da monotonia de edifícios e construções, de forma a melhorar a relação do homem com o meio ambiente, uma vez que o ambiente esteticamente pensado se torna mais atrativo e recreativo para os seus visitantes. Para isso, considera-se que os elementos de desenho para espaços abertos, apontados por Peña 
Salmon (1990) - pavimentos, mobiliário urbano e presença de água, são relevantes para proporcionar maior contribuição estética das áreas verdes.

No entanto, dado ao caratér subjetivo envolvido na avaliação desses elementos, considerou-se o posicionamento de alguns autores (PEÑA SALMON, 1990; PACHECO, 2010; MINDA, 2009; GATTI 2013; BONAMETTI; CRESTANI 2014; HANNES, 2016) que embasaram o processo de observação e a composição dos parêmetros escolhidos.

Para o item pavimentos foi considerado o tipo de uso desse espaço, a intensidade de fluxos, a estratégia de drenagem, conjugados com o ideal estético. Por exemplo, escolha de tipos de pavimento que possibilitem diferentes aplicações ou, em caso de tipos diferentes, utilização de pavimentos atrativos e integrados com os demais. No exemplo de playgrounds infantis a aplicação de piso de borracha, aumenta a segurança, uma vez que ameniza o impacto de quedas. Para auxiliar a drenagem superficial, a aplicação de materiais permeáveis como as concregramas, amplia a superfície das áreas verdes (GATTI, 2013).

Com relação aos equipamentos do mobiliário urbano, por terem um papel muito importante na dinamização do espaço público, estes devem ser resistentes à água, ao desgaste do sol, de fácil manutenção e de uso simples e seguro (PACHECO, 2010). Igualmente sua presença valoriza o desenho urbano, assegura o cumprimento das suas funções, desde que contextualizados ao lugar onde são utilizados, não coloquem a saúde e o bem-estar do usuário em risco, reforcem a identidade do local e não poluam visualmente a paisagem urbana (PEÑA SALMON, 1990; PACHECO, 2010). Quanto ao material utilizado, para um uso correto e bom desempenho, deve estar em harmonia com o ambiente e levar em consideração o clima onde os equipamentos são implantados.

Assumem ainda um papel relevante no mobiliário urbano das áreas verdes as infraestruturas como lanchonetes, lojas, quiosques, sobretudo a partir dos anos 1980, quando os projetos arquitetônicos começaram a evidenciar novas linguagens estéticas ao incluírem atividades comerciais e de serviços no desenho de espaços abertos. Isso ocorreu como forma de atrair usuários a esses espaços e promover maior sensação de segurança, ampliando desta forma a diversidade de usos e a articulação destes espaços com o restante dos elementos morfológicos (BONAMETTI; CRESTANI, 2014).

No que concerne à inclusão de corpos de água como elementos estéticos, a sua utilização em projetos de espaços urbanos pode ser considerada como uma estratégia de melhoria do conforto térmico e visual. Entre os elementos que fazem parte da formação da cidade, os de cunho geográfico-natural, como a água, são encarados como criadores e articuladores entre o natural e o meio construído promovendo o equilíbrio ecossistêmico entre eles. Tornam-se assim elementos fortemente atrativos que convidam ao lazer, à contemplação e promovem o contato humano com a natureza. Contribuem ainda para maior embelezamento e conforto do ambiente desses espaços. Além disso, a presença de água num cenário de área verde, seja por espelhos de água, fontes, lagos, rios, eleva consideravelmente a qualidade ambiental do espaço e por isso se torna elemento hierarquicamente superior (MINDA, 2009; HANNES, 2016). Por estes motivos a presença de elementos com água são considerados na composição da função estética do IQAVU. 


\section{REPRESENTAÇÃO DO CÁLCULO DO IQAVU}

O Índice de Qualidade das Áreas Verdes Urbanas- IQAVU, cujo cálculo é inspirado na forma de cálculo IDH, utiliza a média geométrica, que resulta da raiz n-ésima do produto de " $n$ " valores, onde cada valor corresponde a uma dimensão. O uso da operação de produto no lugar de soma impede que uma dimensão de alto desempenho compense perfeitamente o valor de outra de baixo desempenho. Configuram-se nas equações das seguintes fórmulas:

$$
I Q A V U=\sqrt[3]{F A \times F S \times F E}
$$

Onde:

FA= Função Ambiental

FS=Função Social

FE= Função Estética

\section{FUNÇÃO AMBIENTAL}

$$
F A=\sqrt[3]{I C A \times I F r a g \times I E N}
$$

Onde:

ICA= Índice de Cobertura Arbórea

$$
C A=\frac{\text { Area Copa }}{\text { Area Urbana }}
$$

IFrag= Índice de Fragmentação (Isolado = 0; linear = 0,5; conectado=1) IEN= Índice de Espécies Nativas

$$
\begin{gathered}
I E N=\frac{\text { QNat } \times 100}{\text { total de espécies }} \\
\text { FUNÇÃO SOCIAL }
\end{gathered}
$$

$$
F S=\sqrt[3]{I J \times C A V \times E L}
$$

Onde:

IJ= Índice de Jain 


$$
I J=\frac{\left(\sum_{i=1}^{n} x_{i}\right)^{2}}{n\left(\sum_{i=1}^{n} x_{i}^{2}\right)}
$$

$\mathrm{CAV}=$ Categoria da Área Verde (pública)

$\mathrm{EL}=$ Elementos de Lazer

\section{FUNÇÃO ESTÉTICA}

$$
F E=\sqrt[3]{I M U \times I P A V \times I E A}
$$

Onde:

IMU = Índice (estético) de Mobiliário Urbano

$$
I M U=\frac{M U-1}{4-1}=\frac{M U-1}{3}
$$

IPAV= Índice (estético) de Pavimentos

$$
I P A V=\frac{P A V-1}{4-1}
$$

IEA= Índice de Elementos com Água (Obtido a partir de uma operação de normalização)

A classificação dos resultados compreendidos entre o intervalo de $0-1$, considera a mesma escala de classificação do IDH, conforme descrito na Tabela 1.

Tabela 1: Diferentes escalas de classificação para o ÍQAV

\begin{tabular}{l|r}
\hline \multicolumn{1}{c|}{ Classe } & \multicolumn{2}{|c}{ Pontuação } \\
\hline Muito elevado & $0.80-100$ \\
\hline Elevado & $0,70-0,79$ \\
\hline Médio & 0,55 a 0,69 \\
\hline Baixo & Menos que 0,55 \\
\hline
\end{tabular}

Fonte: adap. da classificação do IDH.

\section{RECORTE GEOGRÁFICO: ÁREA URBANA DE PONTA GROSSA}

Ponta Grossa está localizada no sul do Brasil entre as coordenadas $25^{\circ} 09^{\prime} \mathrm{S}$ e $50^{\circ} 16^{\prime} \mathrm{W}$, especificamente no Segundo Planalto Paranaense, na região dos Campos Gerais, estado do Paraná (Fig. 1). 
Figura 1: Mapa de localização e limites urbanos da cidade de Ponta Grossa, PR

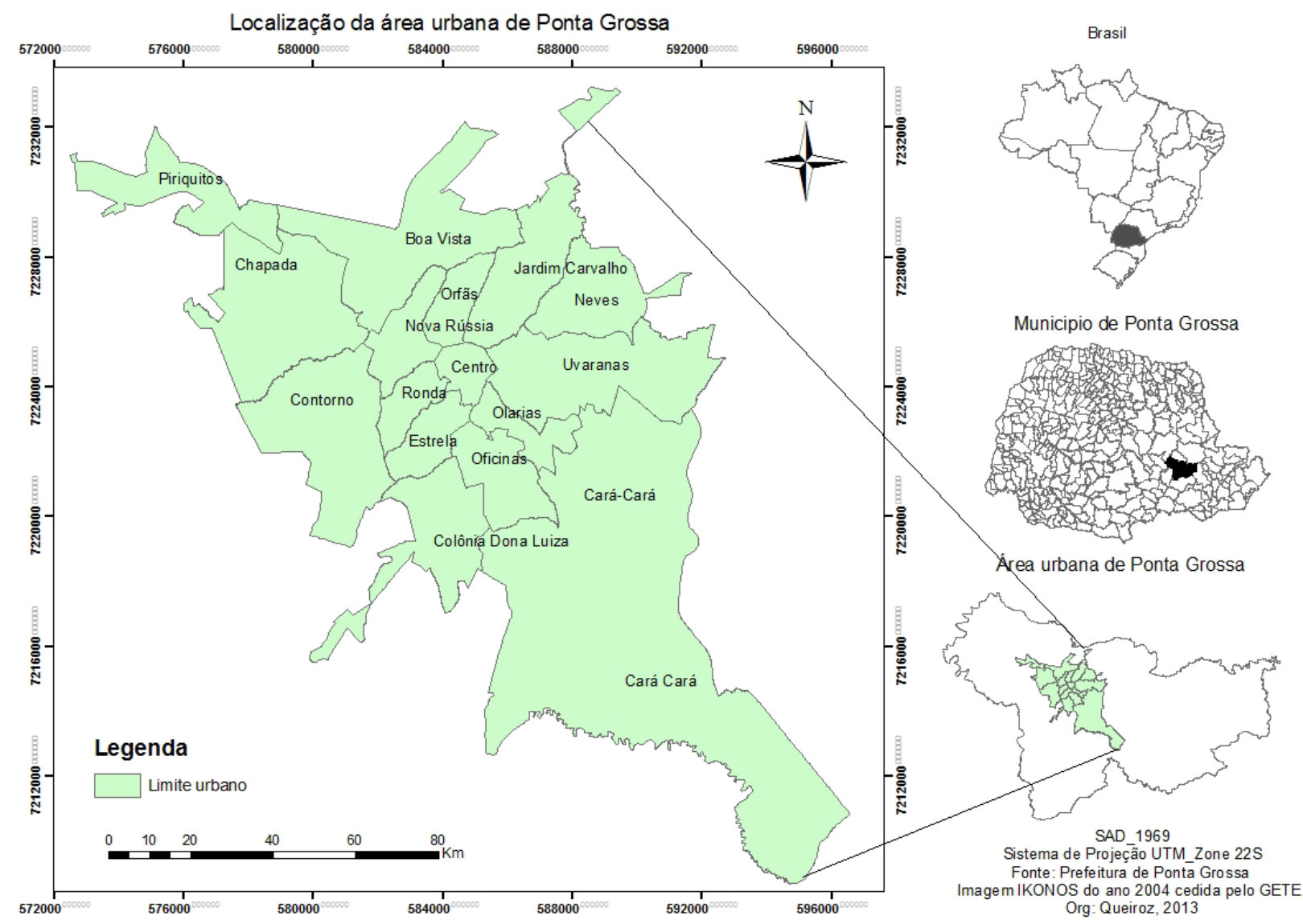

Org: as autoras.

Atualmente se encontra oficialmente dividida em 15 bairros e área central, que ocupam $199 \mathrm{Km}^{2}$, definidos pela lei municipal 9.055/2007, e onde se estima que residam 304.716 (90\%) na área urbana (IBGE, 2018).

\section{AVALIAÇÃO DA QUALIDADE DAS ÁREAS VERDES NA CIDADE DE PONTA GROSSA}

Foram analisadas 40 áreas verdes representadas por 23 praças, oito parques, quatro clubes e cinco outros espaços (Tab. 2), que representam 199.280.00 m² (199.28km²), o que corresponde a aproximadamente $0.5 \%$ da área urbana total, que disponibiliza $7.31 \mathrm{~m}^{2} \mathrm{de}$ área verde por habitante. A classe de praças é a mais representativa, pois para muitos moradores constituem-se as únicas fontes de lazer público e de contato com natureza (PMPG, 2006). 
Tabela 2: Síntese dos dados para a área urbana de Ponta Grossa.

\begin{tabular}{|c|c|c|c|c|c|c|}
\hline \multicolumn{3}{|l|}{ BAIRRO } & \multicolumn{4}{|l|}{ ÁREA VERDE } \\
\hline Nome & Área $\left(\mathrm{m}^{2}\right)$ & Pop & Nome & Área $\left(\mathrm{m}^{2}\right)$ & Categoria & $\%$ \\
\hline \multirow{3}{*}{ Boa Vista } & \multirow{3}{*}{16510042.18} & \multirow{3}{*}{20911} & Cesa & 41706.37 & Pública & \multirow{3}{*}{0.02} \\
\hline & & & Praça Jesuino de Almeida 1 & 916.73 & Pública & \\
\hline & & & Praça Jesuíno de Almeida 2 & 882.01 & Pública & \\
\hline Piriquitos & 8397183.80 & 6471 & Parque Recanto Monteiro & 53240.57 & Privado & 0.02 \\
\hline Cará Cará & 69562994.88 & 18540 & Clube Ponta Lagoa & 399785.73 & Privado & 0.20 \\
\hline \multirow{7}{*}{ Centro } & \multirow{7}{*}{2383980.62} & \multirow{7}{*}{13000} & Praça Santos Andrade & 2004.47 & Pública & \multirow{7}{*}{0.03} \\
\hline & & & Praça Duque de Caxias & 993.50 & Pública & \\
\hline & & & Parque Ambiental & 41819.13 & Pública & \\
\hline & & & Praça Marechal & 3916.01 & Pública & \\
\hline & & & Praça Barão do Rio Branco & 13232.65 & Pública & \\
\hline & & & Praça Barão de Guaraúna & 6763.00 & Pública & \\
\hline & & & Praça João Pessoa & 1942.32 & Pública & \\
\hline \multirow[b]{2}{*}{ Chapada } & \multirow[b]{2}{*}{17011879.48} & \multirow[b]{2}{*}{20499} & Parque Natural Borato & 80847.26 & Pública & \multirow[b]{2}{*}{0.08} \\
\hline & & & Clube América Campestre & 84866.40 & Privado & \\
\hline Colônia Dona Luiza & 10084560.86 & 12367 & & & & \\
\hline \multirow{2}{*}{ Contorno } & \multirow{2}{*}{16037017.36} & \multirow{2}{*}{21519} & Praça sem nome & 878.98 & Pública & \multirow{2}{*}{0.00} \\
\hline & & & Praça sem nome & 510.05 & Pública & \\
\hline \multirow{2}{*}{ Nova Rússia } & \multirow{2}{*}{4658255.44} & \multirow{2}{*}{19824} & Praça Getúlio Vargas & 3452.24 & Pública & \multirow{2}{*}{0.006} \\
\hline & & & Parque Palmeirinha & 9935.09 & Pública & \\
\hline \multirow{2}{*}{ Órfãs } & \multirow{2}{*}{3426217.19} & \multirow{2}{*}{11730} & Praça São José & 12352.76 & Pública & \multirow{2}{*}{0.006} \\
\hline & & & Praça Ana Batista Miró Guimarães & 1394.95 & Pública & \\
\hline \multirow{4}{*}{ Jardim Carvalho } & \multirow{4}{*}{10317945.21} & & Parque Monteiro Lobato & 52672.85 & Pública & \\
\hline & & 15152 & Praça Rotary Internacional & 1171.39 & Pública & 004 \\
\hline & & 10102 & Bosque dos Ingleses & 25488.06 & Pública & 0.04 \\
\hline & & & Praça Antonio Mazaroto & 11411.17 & & \\
\hline & & & Praça Alberto Ansbach & 77.95 & Pública & \\
\hline Neves & 801900126 & 17407 & Praça 31 de Março 1 & 2256.60 & Pública & 0.004 \\
\hline Neves & 8019001.26 & 17407 & Praça 31 de Março 2 & 2370.15 & Pública & 0.004 \\
\hline & & & Praça 31 de Março 3 & 2628.34 & Pública & \\
\hline & & & Parque Nacional Rio Verde & 207921.51 & Pública & \\
\hline & 1616984634 & 41867 & Praça Bom Jesus & 5916.68 & Pública & 015 \\
\hline Uvaranas & 16169846.34 & $4186 \%$ & Praça Simão Nasseh & 3942.73 & Pública & 0.15 \\
\hline & & & Pista de atletismo da UEPG & 98482.35 & P.C & \\
\hline Olarias & 3541170.88 & 7985 & & & & 0 \\
\hline
\end{tabular}


conclusão

\begin{tabular}{|c|c|c|c|c|c|c|}
\hline \multicolumn{3}{|l|}{ BAIRRO } & \multicolumn{4}{|l|}{ ÁREA VERDE } \\
\hline \multirow{3}{*}{ Estrela } & \multirow{3}{*}{3845394.19} & \multirow{3}{*}{6471} & Praça Margarida Malucelli Moro & 1348.25 & Pública & \multirow{3}{*}{0.13} \\
\hline & & & Campo do Guarani & 43761.72 & Privado & \\
\hline & & & Parque Margaritha Masini & 224770.01 & Pública & \\
\hline \multirow{2}{*}{ Ronda } & \multirow{2}{*}{3098426.94} & \multirow{2}{*}{9182} & Parque Boca da Ronda & 393588.97 & Pública & \multirow{2}{*}{0.20} \\
\hline & & & Praça Hilda Roedel & 7423.27 & Pública & \\
\hline \multirow{3}{*}{ Oficinas } & \multirow{3}{*}{6211010.01} & \multirow{3}{*}{17934} & Praça Santa Teresinha & 994.48 & Pública & \multirow{3}{*}{0.02} \\
\hline & & & Praça Símon Bolívar & 7769.73 & Pública & \\
\hline & & & Operário Ferroviário Esporte Clube & 52952.19 & Privado & \\
\hline Total & 199280000.00 & & 40 & 1909084.64 & $\begin{array}{l}33 \mathrm{P} \\
7 \text { Pri }\end{array}$ & 100 \\
\hline Índice A.V (m²/hab) & \multicolumn{5}{|l|}{$7.31 \mathrm{~m}^{2} / \mathrm{hab}$} & \\
\hline Índice de Jain & \multicolumn{5}{|l|}{0.32} & \\
\hline $\begin{array}{l}\text { Área de cobertura } \\
\text { arbórea }\end{array}$ & \multicolumn{5}{|l|}{$801680.00 \mathrm{~m}^{2}$} & \\
\hline
\end{tabular}

Org: as autoras.

A área central é onde se verifica a maior concentração de praças (Fig. 2). Já em relação aos parques, clubes e outras formas de áreas verdes, que apresentam maior dimensão em área, encontram-se distribuídos pelos bairros, com destaque para o Parque Natural do Rio Verde no bairro de Uvaranas, Parque Municipal Boca da Ronda no bairro Ronda e o Parque Margaritha Sanini Masini no bairro Estrela, por serem os parques urbanos de maiores dimensões.

Figura 2: Mapa de localização das áreas verdes da cidade de Ponta Grossa, PR.

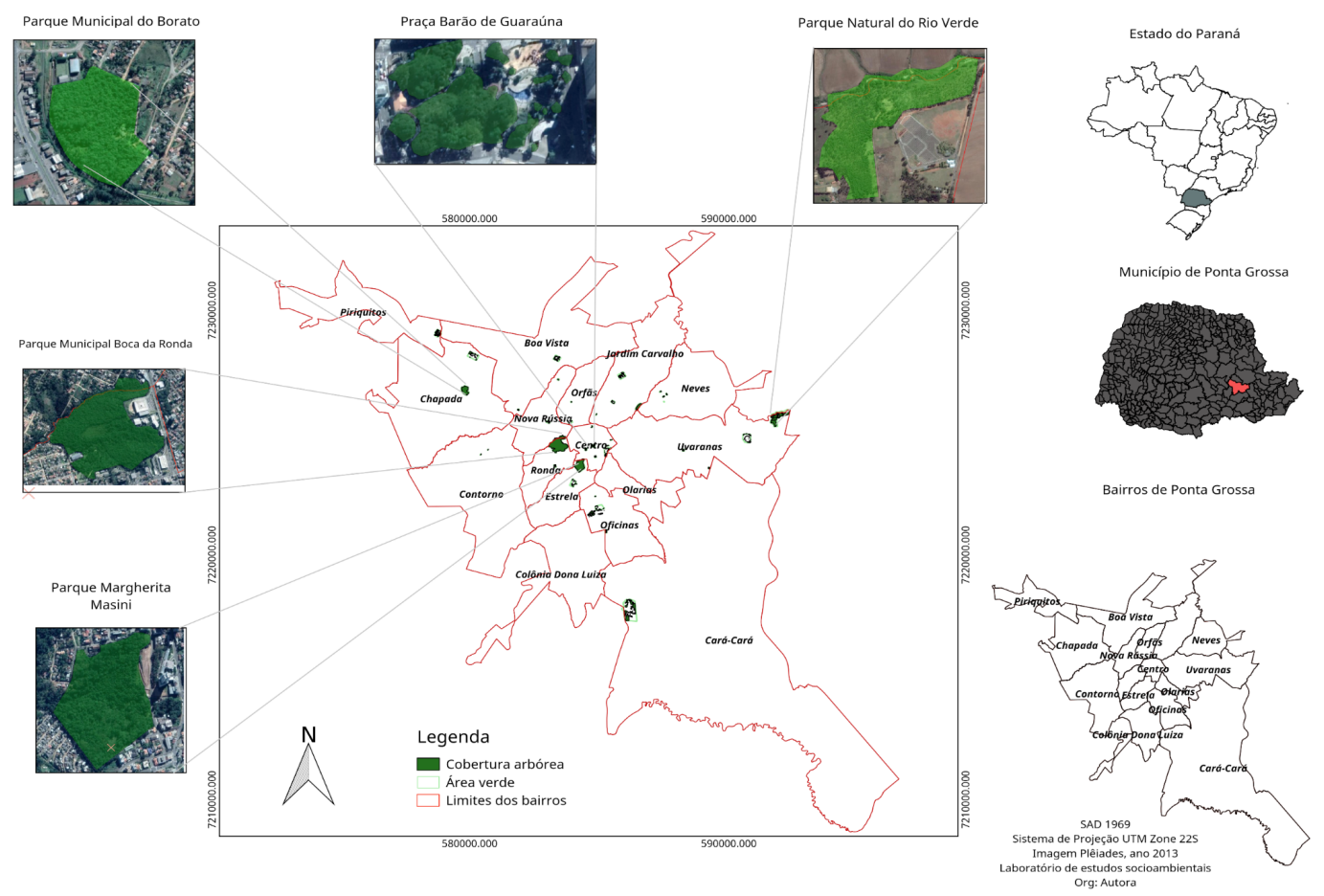

Org.: as autoras. 
Os resultados obtidos pela aplicação do IQAVU (Quadro 3) permitem uma análise sobre o perfil de qualidade das áreas verdes de Ponta Grossa.

\section{Função Ambiental}

O ICA-índice de cobertura arbórea é o que menos contribui para a função ambiental das áreas verdes, com um resultado de 0.04 . O fraco desempenho deste indicador deve-se, principalmente, à baixa representatividade da cobertura arbórea na área urbana.

$\mathrm{Na}$ classificação do indicador Espécies Nativas (EN) foi considerado o valor apresentado por Eurich (2014). Trata-se de um estudo quantitativo da arborização das praças na cidade de Ponta Grossa, no qual a autora citada reportou que 55\% das espécies são exóticas e $44 \%$ são nativas.

Quadro 3: Resultados obtidos do IQAVU para as áreas verdes da cidade de Ponta Grossa, PR.

\begin{tabular}{|l|c|c|}
\hline \multirow{2}{*}{ FUNÇÕES } & INDICADORES & \\
\hline \multirow{4}{*}{ Função ambiental } & ICA & 0,04 \\
\cline { 2 - 3 } & Ifrag & 0,5 \\
\cline { 2 - 3 } & IEN & 0,44 \\
\cline { 2 - 3 } & IFA & $\mathbf{0 , 2 1}$ \\
\hline \multirow{4}{*}{ Função social } & Ijain & 0,32 \\
\cline { 2 - 3 } & ICat. Pública & 0,82 \\
\cline { 2 - 3 } & IEL & 0,7 \\
\cline { 2 - 3 } & IFS & $\mathbf{0 , 5 7}$ \\
\hline \multirow{3}{*}{ Função Estética } & IMO & 0,6 \\
\cline { 2 - 3 } & IPA & 0,7 \\
\cline { 2 - 3 } & IQÁgua & 0,22 \\
\cline { 2 - 3 } & IFE & $\mathbf{0 , 4 5}$ \\
\cline { 2 - 3 } & & $\mathbf{0 , 3 8}$ \\
\hline
\end{tabular}

Org: as autoras

$\mathrm{Na}$ avaliação das manchas de cobertura arbórea para o indicador fragmentação (I-frag), considerou-se que a forma mais presente corresponde à classe isolado-agregado. Essa classificação deve-se ao fato de o maior grupo de áreas verdes constituir as praças, as quais estão localizadas predominantemente em locais intensamente edificados com ruas e superfícies impermeabilizadas, cuja cobertura arbórea está circundada por uma matriz edificada.

Também se verificam quatro manchas (parques municipais) que se encaixam mais na classe conectada de subtipo ramificado. Correspondem a florestas remanescentes florestais anteriores à urbanização, mas, por apresentarem uma ampla cobertura vegetal, oportunizam a constituição de habitats para várias espécies nesses locais. O conjunto destas variáveis resultam no desempenho do índice de função ambiental de 0,21. 


\section{Função Social}

Para a área urbana de Ponta Grossa, o resultado do Índice de Jain foi de 0.32, revelando que a distribuição das áreas verdes por habitante é injusta. Contribuindo para este cenário está a ausência de áreas verdes em dois bairros (Olarias e Colônia Dona Luiza) e a concentração de áreas no Centro e bairros mais próximos aele. O único indicador mais bem avaliado essa função doi o Icat pública, pois a categorias áreas verdes públicas apresentou um peso de $82 \%$ da totalidade desses elementos.

Registraram-se seis áreas de uso privado, entre as quais se destaca o clube Ponta Lagoa, um espaço que integra um lago que permite a prática de pesca, com um bosque e vários jardins, cujo uso está limitado a seus associados. Evidencia-se também o parque Recanto Monteiro, integrando um complexo de piscinas que são mais utilizadas no período do verão e cujo acesso é permitido a utilizadores mediante pagamento de entrada. Ainda na categoria privada, pode-se destacar uma considerável mancha de floresta usada como um bosque dentro de um condomínio privado com uma piscina e uma pista para caminhada, acessíveis apenas aos seus moradores.

Para o indicador de presença de equipamentos de lazer e prática de esportes, obteve-se o registro em cerca de $70 \%$ das áreas verdes, justificado pela concentração de parquinhos infantis em praças, como o caso da Praça Barão de Rio Branco no Centro, e pela infraestrutura de suporte à prática de esporte e atividade física, observada na maioria dos parques públicos e clubes privados que possuem áreas mais amplas.

Os índices que caracterizam a função social para a área urbana de Ponta Grossa totalizaram 0.57 , traduzindo-se em um desempenho muito superior aos 0.27 da função ambiental.

\section{Função Estética}

Da avaliação realizada para caraterizar a função estética cabe ressaltar que o indicador que alcançou melhor classificação foi o índice de mobiliário urbano. Obtendo a classificação de 2.8, a média entre 114 categorias de itens analisados onde estão alocados mais de 580 elementos de mobiliário urbano, entre eles, postes de iluminação, bancos, mesas de refeição, churrasqueiras, parquinhos, aparelhos de ginástica, quadras poliesportivas, sanitários, monumentos, pontos de ônibus, pontos de táxi, banca de revistas e campos de futebol.

As melhores classificações de mobiliário urbano, pavimentos e elementos com água encontraram-se em áreas verdes privadas. Entre elas destaca-se o Clube Ponta Lagoa, com duas piscinas olímpicas, uma piscina infantil, três salões para eventos, nove churrasqueiras, cinco campos de futebol, 13 quadras poliesportivas, nove quiosques, um parque infantil, um lago para pesca esportiva, salão de jogos e 20 postes de iluminação. com notas classificatórias entre o três e o quatro, a diversidade está representada em alguns exemplos destacados nas imagens a, b, c e d da Figura 3. Outra área privada em destaque é o parque Recanto do Monteiro, um amplo espaço verde com várias opções de lazer, como 
piscinas, tubo águas, churrasqueira, restaurante, entre outros, aberto ao público durante os meses de verão, mediante pagamento.

Figura 3: Imagens da infraestrutura do Clube Ponta Lagoa, Ponta Grossa, PR. a) Varanda sobre o lago. b) Pavimento cercado de árvores. c) Parque infantil. d) Vista do lago.

a)

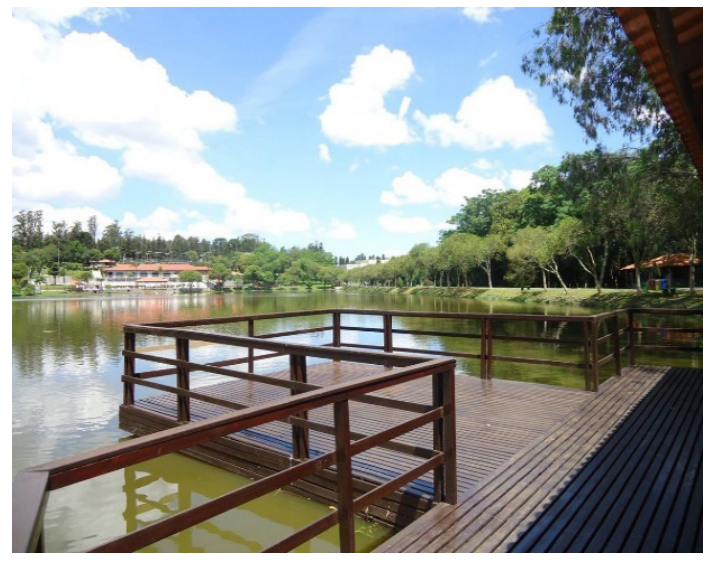

c)

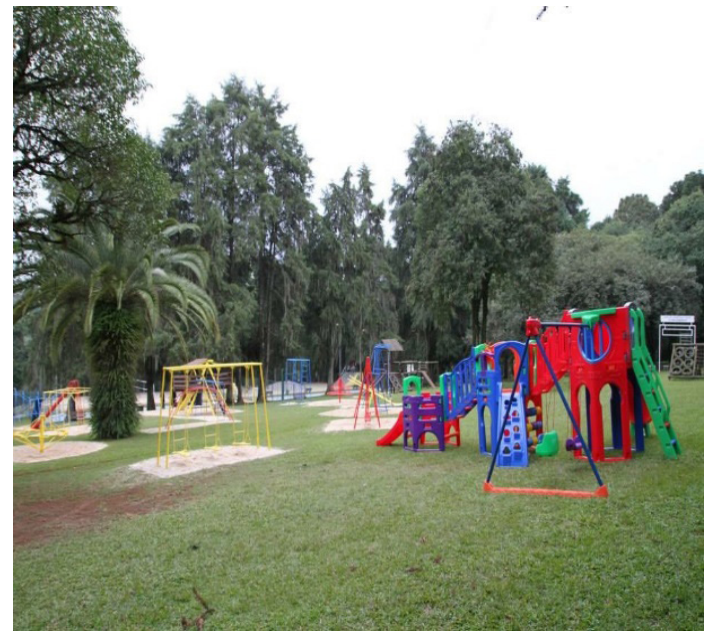

b)

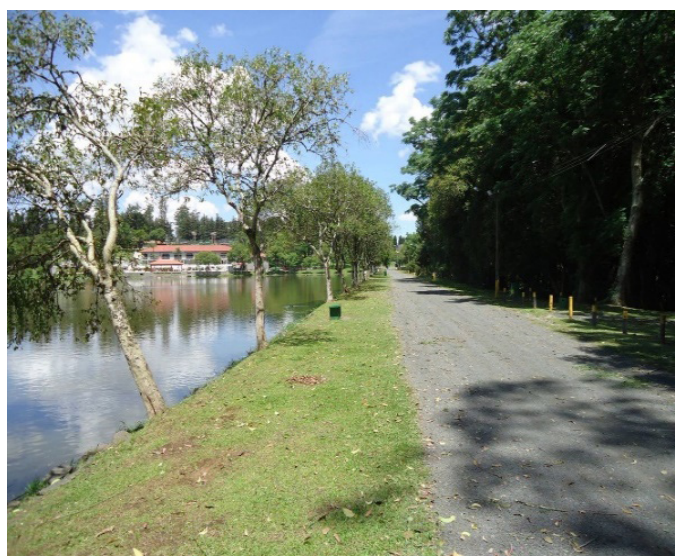

d)

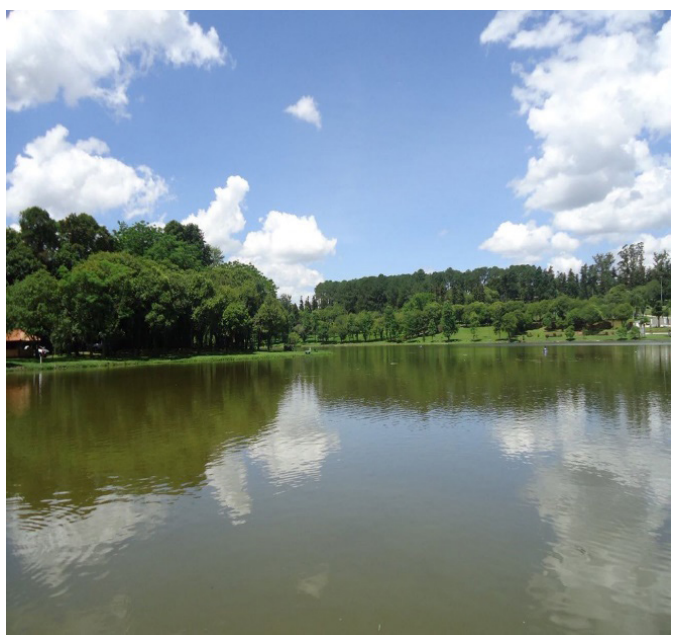

Fonte: www.homologa.clubepontalagoa.com.br. (Acessado em 10 jun. 2018.)

As piores classificações para esta função foram obtidas nas áreas que mais contribuição dão à função ambiental, por conta da expressiva mancha arbórea. Entre essas áreas estão os parques Margharita Masini e Rio Verde, os quais em um passado recente já foram opções relevantes de lazer para a população, mas atualmente têm sido alvo de vandalismo e apresentam fortes sinais de abandono e desgaste da sua infraestrutura, apesar das várias tentativas da Secretaria do Meio Ambiente em revitalizar esses lugares.

Entre as áreas verdes públicas que se destacam positivamente na composição do mobiliário urbano e pavimentos está o Parque Monteiro Lobato com seis bancos de concreto, 52 postes de iluminação, 12 lixeiras, sete mesas de refeição em concreto, um parquinho infantil, sete aparelhos de ginástica e seis campos de esporte. Neste quesito, entra também o Parque Ambiental, na área central, com diversidade de itens, tais como um parque infantil, duas quadras esportivas, dois sanitários, oito lixeiras de plástico e sete aparelhos de ginástica. 
As praças, de forma geral, apresentam um padrão na composição do seu mobiliário e desenho; os bancos são majoritariamente de madeira, com exceção da Praça Barão do Rio Branco e alguns itens de mobiliário apresentam sinais de degradação, conforme se destaca na Figura 4.

Figura 4: Banco das praças de Ponta Grossa, PR.
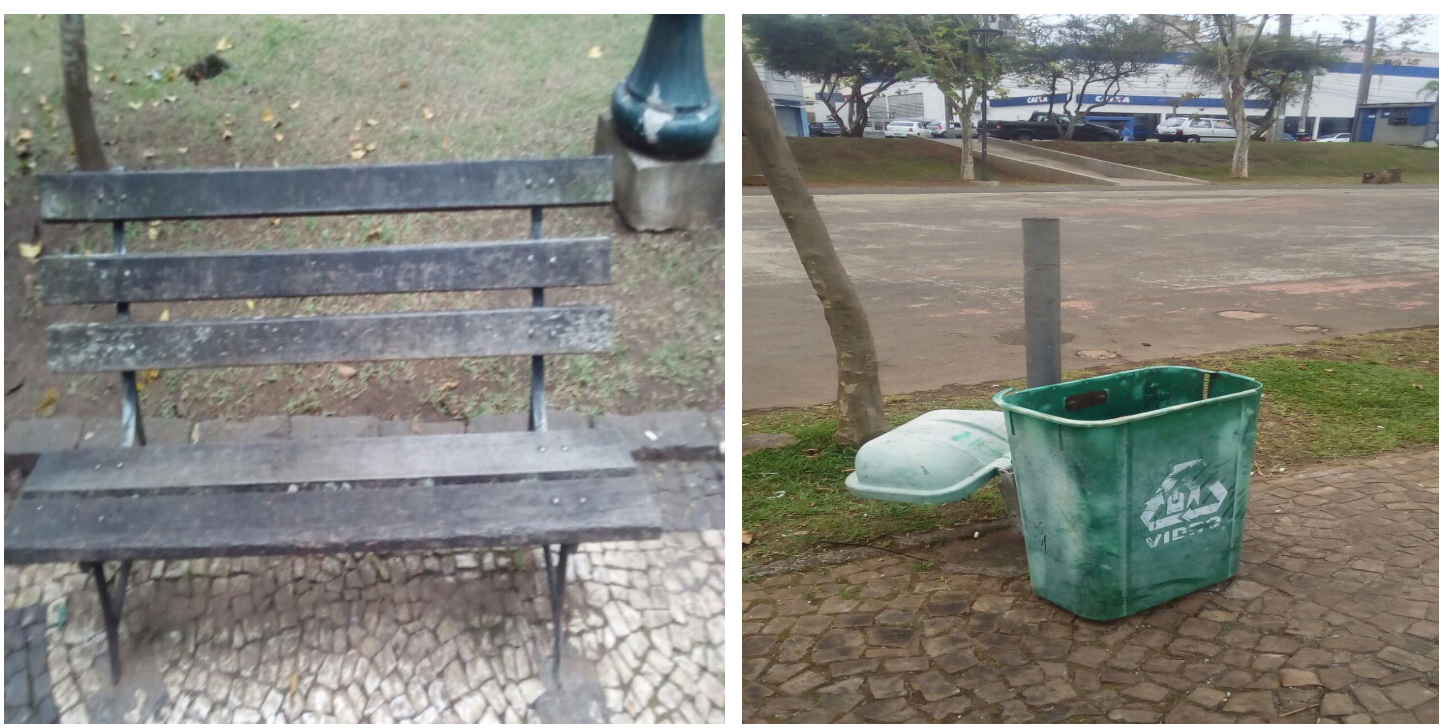

Fonte: as autoras.

No item pavimentos, foram analisados 15 tipos diferentes quanto à sua segurança e conservação, que resultou na classificação regular. Entre eles, os mais frequentes são as calçadas, concreto e asfalto, e os que apresentam mais problemas de conservação são os pavimentos com calçada, esteticamente mais adequados, especialmente, em praças; no entanto, apresentaram problemas no critério conservação, com alguns blocos soltos e outros faltando (Fig. 5).

Figura 5: Calçada com sinais de degradação em praça de Ponta Grossa, PR.

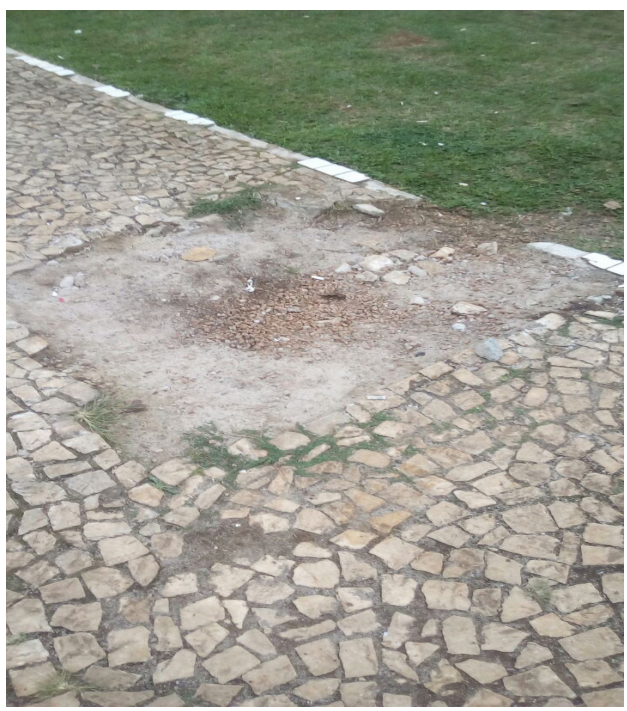

Fonte: as autoras. 
A presença do elemento água foi registrada em $22 \%$ das áreas verdes na cidade de Ponta Grossa, e com maior ocorrência em áreas verdes privadas com a inclusão de piscinas e lagos. Nas praças públicas, esse elemento está presente sob a forma de fontes, e a presença de espelhos de água foi registrada de forma natural no Parque Municipal Rio Verde.

Diante destes cenários a classificação para a função estética resultou em 0.45 de contribuição no IQAVU.

Em síntese, o valor do IQAVU atribuído à cidade de Ponta Grossa é de 0,38 e a fragilidade maior se encontra no índice da função ambiental seguido pela função estética, e o maior valor alcançado foi o da função social.

\section{CONCLUSÕES}

O resultado de 0.38 para o IQAVU da cidade de Ponta Grossa permitiu identificar claramente que a qualidade destes espaços é muito baixa. Porém, mais que o significado de um valor numérico, a potencialidade deste índice para o planejamento urbano, reside na identificação da função que está mais debilitada, neste caso, a função ambiental.

Perante este resultado, fica evidente que o poder público poderá melhorar a qualidade das áreas verdes na cidade, caso forem tomadas medidas que interfiram diretamente na função ambiental, como por exemplo, diminuir a quantidade de espécies exóticas com replantio de nativas e implantar mais espécies arbóreas.

O perfil deste índice permite ainda concluir que o desempenho da função estética das áreas verdes em Ponta Grossa revelou-se baixo, principalmente pela falta de manutenção nos equipamentos do mobiliário urbano.

O melhor desempenho deste índice está na função social, devendo-se sobretudo à percentagem de espaços de categoria pública, alcançando, desta forma, mais pessoas e mais justiça social.

Conclui-se ainda que a melhor forma de potencializar as funcionalidades das áreas verdes é direcionando a estratégia para os aspetos estéticos do desenho desses espaços, em especial à manutenção dos que já existem, investindo mais atenção ao desenho arquitetônico das áreas verdes públicas e em ações de sensibilização para a preservação do patrimônio público, para que possam constituir-se em um referencial de espaço verde dentro da comunidade.

\section{REFERÊNCIAS}

ALMEIDA, A.R. de; ZEM, L.M.; BIONDI, D. Relação observada pelos moradores da cidade de CuritibaPR entre a fauna e árvores frutíferas. 2009. Disponível em: http://www.revsbau.esalq.usp.br/artigos_ cientificos/artigo70. Acesso em: 11 set. 2019.

ALMEIDA, C. O Verde na cidade. Reflexão inspirada na cidade de Coimbra (Portugal). Cadernos de Geografia n. 34, p.3-9, 2015. 
AMORIM FILHO, O.B; SERRA, R. V. Evolução e perspectivas do papel das cidades médias no planejamento urbano e regional. In: ANDRADE, T. A.; SERRA, R. V. (Orgs.). Cidades Médias Brasileiras. Rio de Janeiro: IPEA, 2001. p. 1-34.

AZEVEDO, J.; GONÇALVES, A. Manual de Boas Práticas em Espaços Verdes. Bragança: Câmara Municipal, 2010.

BARGOS. Mapeamento e análise de áreas verdes urbanas em Paulínia (S.P). Estudo com aplicação de Geotecnologias. Sociedade \& Natureza, n.1 p. 143-156, 2012.

BERNATZKY, A. The contribution of trees and green spaces to a town climate. Energy and building, International Council for Research and Innovation in Building and Construction, v. 5, p. 1-10, 1992.

BOLUND, P. HUNHAMMAR, S. Ecosystem services in urban areas. Ecological Economics, v. 29, n.8, p. 293-301, 1999.

BONAMETTI, J.H.; CRESTIANI, A.M.Z. Espaços abertos públicos e as correntes paisagísticas contemporâneas. Revista: Oculum Ens., v. 11, n. 2, p. 231-243, 2013.

BRUN, F.G.K; LINK, D.; BRUN, E.J. O emprego da arborização na manutenção da biodiversidade de fauna em áreas urbanas. Revista da Sociedade Brasileira de Arborização Urbana, v. 2, n. 1, p. 117- 127, 2007.

CAVALHEIRO, F.; DEL PICCHIA, P.C.D. Áreas verdes: conceitos, objetivos e diretrizes para o planejamento. In: ENCONTRO NACIONAL SOBRE ARBORIZAÇÃO URBANA, 4, 1992, Vitória. Anais... p. 2938.

CONTE. C.H. Cidades médias: discutindo o tema. Rev. Sociedade e Território, v. 25, n. 1, p.45-61, 2013.

CORRÊA, R.L. O Espaço urbano. 3.ed. São Paulo: Ática,1995.

DELGADO, M. El espacio público como ideología. Barcelona: Libros de la Catarata, 2011.

DETZEL, V. A. Arborização urbana: importância e avaliação econômica. In: CONGRESSO BRASILEIRO SOBRE ARBORIZAÇÃO URBANA, 4., 1992, Vitória. Anais... Vitória: SBAU, 1992. p. 39-52.

EURICH, Z.R.S. As praças de Ponta Grossa: Arborização urbana, infraestrutura e distribuição espacial. Ponta Grossa, 2014. Dissertação (Mestrado em Gestão do Território) - Universidade Estadual de Ponta Grossa, UEPG.

FORMAN, R.T.; GODRON, M. Landscape Ecology. New York: Wiley, 1986.

GATTI, S. Espaços públicos, diagnóstico e metodologia de projeto. Coordenação do Programa Soluções para cidades. São Paulo: ABCP, 2013.

GUZZO, P. Estudo dos Espaços livres de uso público da cidade de Ribeirão Preto/SP, com detalhamento da cobertura vegetal e áreas verdes públicas de dois setores urbanos. Rio Claro, 1999. Dissertação (Mestrado em Ecologa Vegetal) - Universidade Estadual Paulista Júlio de Mesquita Filho, UNESP.

HANNES, E. Desenho ambiental e forma urbana: o caso do bairro de Riverside. Arquitextos, v. 196, n. 7 , p. 1-1, 2016.

HARDER, I.C.F; ROBERVAL, C.S.R.; TAVARES, A.R. Índices de área verde e cobertura vegetal para as praças do Município de Vinhedos, SP. Rev. Árvore, v.30, n. 2, p. 277-282, 2006.

IBGE - Instituto Brasileiro de Geografia e Estatística. Cidades. Disponível em:.www.ibge.gov.br Acesso em: 12 jul. 2018.

JAIN, R.; CHIU, D.M.; HAWE, W. A Quantitative Measure of Fairness and Discrimination for Resource Allocation in Shared Computer Systems. DEC Research Report, TR-301, 1984.

JIM, C.Y. Tree-canopy characteristics and urban development in Hong Kong. The Geographical Review, v.79, n.2, p. 210- 255, 1989.

LAMAS, J.M.R.G. Morfologia urbana e desenho da cidade. Lisboa: Fundação Calouste Gulbenkian, 2004. $2 \mathrm{v}$.

LLANDERT, L.R.A. Zonas libres y espacios libres en la ciudad. Madrid: Instituto de estudios de administracion local, 1982. 
LINDENMAIER, D.S. Aorganização da vegetação arbórea na paisagem urbana de Cachoeirado Sul, RS. Florianópolis, 2013. Dissertação (Mestrado em Geografia) - Universidade Federal de Santa Catarina, UFSC.

MARCHANT, E.; MARCHANT H. As exóticas e invasoras. In: SANDE SILVA, J. (Ed.) Do freixo à bétula, as outras espécies da floresta Portuguesa. 2007, p. 179-198. (Árvores e Florestas de Portugal, 5).

MINDA, J.E.C. Os Espaços Livres Públicos e o contexto local: o caso da praça principal dePitalito-HuiaColômbia. Brasília, 2009. Dissertação (Mestrado em Arquitetura e Urbanismo) - Universidade de Brasilia, UnB.

NAHAS, M.I.P. Metodologia de Construção de Índices e Indicadores Sociais, como Instrumentos balizadores da gestão municipal da qualidade de vida urbana: uma síntese da experiência de Belo Horizonte. In: HOGAN, D. et al. (org.): Migração e ambiente nas aglomerações urbanas. Campinas: UNICAMP, 2001. p.465-487.

NASCIMENTO, E.D.; MATIAS, R.L.F. Expansão urbana e desigualdade sócio-espacial: uma análise da cidade de Ponta Grossa (PR). RA'E'GA, n. 23, p. 65-97, 2011.

NUCCI, J.C. Qualidade Ambiental e adensamento urbano: um estudo de ecologia e planejamento da paisagem aplicada ao Distrito de Santa Cecília- MSP 150p. 2 ed. Curitiba, 2008.

NUCCI, J.C.; WESTPHALEN, L.A.; BUCCHERI-FILHO, A.T. et al. Cobertura vegetal no bairro Centro de Curitiba/PR. Revista GEOUERJ, número especial, Rio de Janeiro, 2003.

OLIVEIRA, C.H. Planejamento ambiental na cidade de São Carlos (SP) com ênfase nas áreas públicas e áreas verdes: diagnóstico e propostas. São Carlos, 1996. Dissertação (Mestrado em Ecologia) - Universidade Federal de São Carlos, UFSCar.

PMPG. Plano Diretor Municipal de Ponta Grossa. 1992, 2006. Disponível em: www.pontagrossa.pr.gov. br. Acesso em: 15 abr. 2018.

PACHECO, C.P.N. Equipamentos Nos Espaços verdes para a $3^{\text {a }}$ idade-O caso Quinta das Conchas. Lisboa, 2010. Dissertação (Mestrado em Arquitetura) - Universidade Técnica de Lisboa.

QUEIROZ, D.A.H.O. Cobertura vegetal, espaços livres e áreas verdes em Ponta Grossa-PR: mapeamento, tipificação e análise. Ponta Grossa, 2014. Dissertação (Mestrado em Gestão do Território) - Universidade Estadual de Ponta Grossa, UEPG.

RUMBLE, H.; ANGEOLETTO, F.; CONNOP, S. et al. Understanding and applying ecological principles in cities. In: LEMES de OLIVEIRA, F.; MELL, I. (Eds.). Planning Cities with Nature: Theories, Strategies and Methods. Amsterdam: Springer Naure, 2019.

SANTOS, R.F. Planejamento Ambiental: teoria e prática. São Paulo: Oficina de Textos, 2004.

SAHR, C.L. Estrutura interna e dinâmica social na cidade de Ponta Grossa. In: DITZEL, C. de H. M; SAHR, C.L. (Orgs). Espaço e cultura: Ponta Grossa e os Campos Gerais. Ponta Grossa: Ed. UEPG, 2001. p. 13-36.

PEÑA SALMON, A.C. Usos, funciones y caracteristicas de las Plantas en el deseño del paisaje: funciones ecológicas. Mexicali: UBC, 1990. 232 p.

SILVA, J.F.D. Contributo dos espaços verdes para o bem-estar das populações: estudo de caso em Vila Real. Coimbra, 2014. Dissertação (Mestrado em Geografia Humana) - Universidade de Coimbra, Portugal. SILVA. A.L. Breve discussão sobre o conceito cidade média. Geoingá, Maringá, v. 5, n. 1, p. 58-76, 2013.

SPOSITO, M.E.B. Desafios para o estudo das cidades médias In: SEMINÁRIO INTERNACIONAL DE LA RED IBEROAMERICANA DE INVESTIGADORES SOBRE GLOBALIZACIÓN Y TERRITÓRIO, 11, 2010, Mendoza. Anais... Mendoza: UNCUYO, 2010. p. 1-18.

THOMPSON, C. Urban open space in the 21st century. Landscape and Urban Planning, v. 60, p. 59-72. 2002.

Data de submissão: 19/mar./2019

Data de aceite: $21 /$ set./2019 